\title{
Direct and indirect cost of schizophrenia in outpatients treated in a tertiary care psychiatry unit
}

\author{
J de Silva ${ }^{1}$, R Hanwella ${ }^{2}$, de Silva ${ }^{2}$ \\ (Index words: schizophrenia, cost analysis, cost of illness, Sri Lanka, economics)
}

\begin{abstract}
Objective To estimate the direct and indirect cost of care incurred by patients with schizophrenia attending a tertiary care psychiatry unit in Colombo.

Methods Study was carried out at the National Hospital of Sri Lanka. Systematic sampling selected every second patient with an ICD-10 clinical diagnosis of schizophrenia presenting to the clinic during a two month period. Investigator administered semi-structured questionnaire was used for data collection.

Results Sample consisted of 91 patients. Direct cost was defined as cost incurred by the patient (out of pocket expenditure) for outpatient care. Mean cost of a clinic visit was Rs. 500. Of the clinic visit cost, highest proportions were travel cost (39.8\%) and medication (26.4\%). Sixty four (70.3\%) had received informal care. The mean cost of informal care during the entire course of the illness was Rs. 33, 540. Mean indirect cost was Rs. 150,190 .

Conclusions Despite low direct cost of care, indirect cost and cost of informal treatment results in substantial economic impact on patients and their families. It is recommended that economic support should be provided for patients with disabling illnesses such as schizophrenia, especially when patients are unable to engage in full time employment. There is a need to educate the public regarding higher cost of care by traditional healers and other informal modes of treatment compared to Western medical care.
\end{abstract}

Ceylon Medical Journal 2012; 57: 14-18

\section{Introduction}

Even though in Sri Lanka public health care is free at the point of delivery, illness results in financial cost to patients. Among the poor, illness can worsen poverty. Schizophrenia is a chronic illness which results in significant cost to the patient, family and health care services.

The economic cost of illness can be broadly divided into direct and indirect costs. Direct costs are those for which payments are made [1, 2]. A portion of direct cost is borne by health care services while patients and their carers or health insurance payments finance the rest. Cost of medicines constitutes a substantial portion of direct costs. In Sri Lanka it was estimated that medicines accounted for a third of direct costs across all types of illness [3, 4]. In India almost three quarters of out of pocket expenditure was spent on purchasing medication [5]. Transport costs, cost of nutritious food for the ill person, food and accommodation costs for accompanying person are other types of direct costs borne by patients [6]. Indirect costs are defined as the cost of productive time loss resulting from illness [1]. This includes the cost of lost productivity in the patient as well in care givers.

Household out of pocket expenditure has a significant effect on poverty in low and middle income countries with many poor resorting to borrowing and selling of assets to finance this cost [5]. In India it is estimated that $2.2 \%$ of the population fall into poverty because of out of pocket expenditure.

Most studies estimating the economic cost of schizophrenia have been carried out in high income countries [1]. Although schizophrenia is a chronic illness with great cost to the individual and society, there is little data available about the economic cost of schizophrenia in Sri Lanka. The objective of this study was to estimate the direct and indirect cost of care incurred by patients with schizophrenia attending a tertiary care psychiatry unit in Colombo.

\section{Methods}

The study was carried out at the out patient psychiatry clinic of the National Hospital of Sri Lanka. Systematic sampling selected every second patient with an ICD-10 clinical diagnosis of schizophrenia presenting to the clinic during a two month period. Patients over 60 years of age were excluded as older patients are more likely to have co-morbid illness which increase illness related expenses. Patients too ill to participate and patients refusing consent were also excluded. Data were collected using an investigator-administered, semi-structured questionnaire, from both the patient and at least one other family member for cross validation.

\footnotetext{
${ }^{1}$ Teaching Hospital, Anuradhapura, Sri Lanka, ${ }^{2}$ Department of Psychological Medicine, Faculty of Medicine, Colombo, Sri Lanka.

Correspondence: VdeS, e-mail: <varunidesilva2@yahoo.co.uk>. Received 30 September 2011 and revised version accepted 13 January 2012. Competing interests: none declared.
} 
Direct cost was defined as 'out of pocket expenditure (direct spending of a household on medical care) for outpatient care'. Direct cost was calculated on expenditure for the last clinic visit, based on data provided by the patients and their care givers. Informal treatment was defined as 'care received by the patient from someone other than a MBBS qualified doctor'. Long term indirect cost was defined as 'the loss of income to the patient or to the caregiver due to unemployment or poor attendance as a result of the illness'.

Written informed consent was obtained from patients as well as relatives who participated in the interview.
Approval for the study was obtained from the Ethics Committee of the National Hospital of Sri Lanka. 13.0.

Data analysis was carried out using SPSS version

\section{Results}

The sample consisted of 91 patients (Table 1). Forty Nine (53.8\%) were female. The age range was $16-60$ years. Fifty (54.9\%) were unmarried. Thirty two patients (35.2\%) were unemployed. Twelve (13.2\%) were full time house wives. Forty (44.0\%) were engaged in income generating employment.

Table 1. Characteristics of the sample

\begin{tabular}{|c|c|c|c|}
\hline & $\begin{array}{c}\text { Male } \\
\text { Frequency (\%) }\end{array}$ & $\begin{array}{c}\text { Female } \\
\text { Frequency (\%) }\end{array}$ & $\begin{array}{c}\text { Total } \\
\text { Frequency (\%) }\end{array}$ \\
\hline \multicolumn{4}{|l|}{ Age } \\
\hline $16-30$ years & $13(31.0)$ & $17(34.7)$ & $30(33.0)$ \\
\hline $31-50$ years & $21(50.0)$ & $13(26.5)$ & $34(37.4)$ \\
\hline 51-60 years & $8(19.0)$ & $19(38.8)$ & $27(29.7)$ \\
\hline \multicolumn{4}{|l|}{ Marital status } \\
\hline Never married & $25(59.5)$ & $25(51.0)$ & $50(54.9)$ \\
\hline Married & $17(40.5)$ & $22(44.9)$ & $39(42.9)$ \\
\hline Divorced & $0(0)$ & $2(4.1)$ & $2(2.2)$ \\
\hline \multicolumn{4}{|l|}{ Employment status } \\
\hline Unemployed & $10(23.8)$ & $22(44.9)$ & $32(35.2)$ \\
\hline Full time housework & $0(0)$ & $12(24.5)$ & $12(13.2)$ \\
\hline Employed & $30(71.4)$ & $10(20.4)$ & $40(44.0)$ \\
\hline Student & $1(2.3)$ & $3(6.1)$ & $4(4.4)$ \\
\hline Retired & $1(2.3)$ & $2(4.1)$ & $3(3.3)$ \\
\hline \multicolumn{4}{|c|}{ Monthly household income } \\
\hline$<$ Rs.6000 & $6(14.3)$ & $7(14.3)$ & $13(14.3)$ \\
\hline Rs. $6001-15,000$ & $12(28.6)$ & $18(36.7)$ & $30(33.0)$ \\
\hline >Rs.15001 & $24(57.1)$ & $24(49.0)$ & $48(52.7)$ \\
\hline \multicolumn{4}{|l|}{ Years of education } \\
\hline $0-6$ years & $9(21.4)$ & $2(4.1)$ & $11(12.1)$ \\
\hline 7-11 year & $20(47.6)$ & $24(49.0)$ & $44(48.4)$ \\
\hline >11 years & $13(31.0)$ & $23(46.9)$ & 36(39.6) \\
\hline
\end{tabular}


Table 2. Out of pocket expenditure of outpatient clinic attendance

\begin{tabular}{lccc}
\hline & $\begin{array}{c}\text { Number of patients } \\
\text { incurring cost }(\%)\end{array}$ & $\begin{array}{c}\text { Mean expenditure } \\
(N=91)\end{array}$ & 95\% confidence interval \\
\hline Travel & $89(97.8)$ & Rs. 200 & $156-244$ \\
Meals & $43(47.3)$ & Rs. 50 & $36-68$ \\
Medication & $21(23.1)$ & Rs.130 & $56-209$ \\
Investigations & $13(14.3)$ & Rs. 84 & $21-147$ \\
Total & 91 & Rs. 500 & $377-627$ \\
\hline
\end{tabular}

Table 3. Estimated cost of informal care

\begin{tabular}{ll}
\hline Type of Treatment & Cost range (SLR) \\
\hline Pooja & Rs. 100-300 \\
Thovil & Rs. 20,000-50,000 \\
Tying a blessed thread & Rs. 100-300 \\
Faith Healing & Free- Rs. 500 \\
Counseling & $>$ Rs. 1,000 \\
Ayurveda and indigenous Medicine & Rs. $1,000-3,000 /$ month \\
\hline
\end{tabular}

\section{Direct cost}

Direct costs included cost of travel, meals for patient and accompanying persons, medications, investigations, lodging and other unspecified expenses (Table 2).

Travel costs accounted for the highest proportion of the total cost of a clinic visit (39.8\%). Patients accompanied by family members spent more on travel and meals. Many patients travelled early in the morning and had breakfast from a boutique or the hospital canteen. Few patients spent on mid-morning tea. Those who travelled from far spent on lunch as well. Some patients brought food from home in order to minimise the cost. Medication accounted for $26.4 \%$ of the total cost. Only 21 patients had purchased medication. Patients purchased medication when prescribed medication was not available in the clinic. Even when medication was available, some patients purchased it because of convenience. Similarly, because of convenience, some patients had investigations done at private laboratories even if they were available in the hospital. Only 13 patients (14.3\%) incurred cost for investigations. Mean expenditure for a clinic visit was Rs. 500/patient (95\% CI 377-627).

\section{Expenditure related to informal treatment}

Common forms of informal care included ritualistic treatment, Ayurveda treatment, 'Bodhi Pooja', 'Hindu Pooja', 'Thovil' ceremonies (exorcism), 'Pirith' chanting by Buddhist monks, faith healing and wearing threads and talisman which were blessed. Some had attended 'counselling sessions' provided by people with no formal qualifications.

Seventy eight patients (71.6\%) had received informal treatment. 'Bodhi Pooja' was carried out by 43 (47.3\%), 'Thovil' by 26 (28.6\%) and blessed threads were worn by 26 patients (28.6\%). Of the 78 who had received informal treatment, 41 (45.1\%) had received it prior to seeking Western medical care while 23 (25.3\%) sought informal treatment while receiving Western psychiatric treatment.

Table 3 shows the average cost of an episode of different types of informal treatment as estimated by patients and care givers. The most costly treatment was “Thovil” ceremony which cost between Rs. 20,000-50,000. The mean cost of informal care during the entire course of the illness was Rs. 33,540 (95\% CI 16591-50503). Of those who received informal care 14 patients (15.4\%) spent $\leq$ Rs. 1000 . Nine patients (9.8\%) reported they had spent $\geq$ Rs. 100,000 .

\section{Long term indirect cost of illness}

Twelve males (28.5\%) and 18 females (36.7\%) had 
lost their job due to the illness. Nine males and 5 females who were daily paid workers reported poor work attendance leading to financial loss. Financial loss due to loss of employment was calculated by multiplying the monthly or the daily income by the number of months or days unemployed. Mean cost due to loss of employment and poor attendance was Rs. 142,295 (95\% CI 83,623200,966). In 15 patients the loss of income was between Rs. 200,000-500,000 and in seven patients more than Rs. 500,000. Caregivers of 7 patients had incurred financial loss by giving up employment or due to absenteeism as a result of caring for the patient. The total mean indirect cost was Rs. 150,190 (95\% CI 91,579-208,794).

\section{Discussion}

In this study we described the direct and indirect cost of illness incurred by patients with schizophrenia and their families. We found that the indirect cost was higher than the cost of direct care. Mean indirect cost due to loss of employment and poor attendance was Rs. 142,295. The mean direct cost of a clinic visit was Rs. 500 . The major proportion of direct cost (39.8\%) was travel expenditure. Medication accounted for $26.4 \%$ of a clinic visit cost.

Cost of informal care was significant in our sample with a mean cost of Rs. 33,540. This is of concern because a substantial proportion of patients sought informal care and it was much more costly than Western psychiatric treatment. The proportion of our patients seeking informal care (71\%) was similar to that in India where the first contact for $68 \%$ of patients with psychiatric illness was a faith healer [7].

Both direct and indirect costs vary considerably according to the type of illness. Indirect costs are high when the illness is chronic, disabling and affects a relatively young population. Comparison of cost of schizophrenia and diabetes in India shows that the indirect cost of schizophrenia amounting to Indian rupees (IR) 8620 was much higher than that of diabetes (IR 4172) [8]. However, the direct cost borne by the family in schizophrenia was lower (IR 4460) compared to diabetes (IR 9932). The higher direct cost in diabetes was explained by the higher cost of medication, dietary modification and investigations. Even though diabetes is a chronic illness it is less disabling than schizophrenia and therefore has less indirect cost.

A study from Sri Lanka found that the indirect cost of many illnesses is small [6]. A household survey in Colombo reports that loss of income did not occur in many illness because a large proportion of acute illnesses was in children and illness in economically active adults were not serious enough to affect work, and because the majority experiencing chronic illness and hospital admission were economically inactive [3]. A high percentage of patients in our sample were in the economically active age group and were unemployed because of the illness. This explains the high indirect cost.

The direct out of pocket expenditure reported by our patients is relatively less than that reported in other countries. In India the direct annual cost borne by patients with schizophrenia was IR 4460 [8]. The main difference between the direct cost in the Indian patients and our sample was the cost of drugs. The mean cost of medication for a six month period in our sample was US\$ 8 compared to US\$ 24 (IR1203) in the Indian patients. While Indian patients purchased antipsychotic drugs to the value of US\$19.6, the health provider had supplied antipsychotics only to the value of US\$ 0.70 . This shows that the free health care provided in Sri Lanka had reduced direct cost to the patient significantly.

Out of pocket expenditure for illness is known to precipitate and worsen poverty in the vulnerable. For low income families, spending $10 \%$ of household income on illness can be potentially catastrophic $[9,10]$. This could force households to cut their spending on essentials such as food, clothing and education and trigger off sales of productive assets or resort to high cost borrowing from money lenders [11]. This phenomenon is described as the 'medical poverty trap'.

Free health care services in urban Sri Lanka, protected the majority of poor households against high out of pocket payments $[3,11]$. Despite this, about $10 \%$ of our patients said they borrowed money from money lenders or pawned jewellery to meet health care costs.

While the state health care sector minimised direct cost of illness, it is of concern that in patients with schizophrenia, informal treatment from traditional healers resulted in significant financial cost. The stigma of mental illness, cultural beliefs about origins of mental illness and lack of awareness about Western medical care all contribute to the high cost of informal care.

The study had several limitations. It was carried out in a tertiary care unit in Colombo where availability of medication and facilities for investigations are more than in other parts of the country. This would have minimised out of pocket expenditure. The travel cost could also be more in rural areas where people have to travel longer distances. Cost estimates were based on reports by patients and family members and recall of the past events would have influenced the estimates. The calculation of indirect long-term costs has the potential for most inaccuracies. We only estimated the indirect cost due to loss of employment and poor work attendance but did not estimate the indirect cost of patients never employed due to the illness.

Our findings have important implications. This study showed that despite low direct cost of care, indirect cost and cost of informal treatment results in substantial 
economic impact on patients and their families. It is recommended that economic support should be provided for patients with disabling illnesses such as schizophrenia, especially when patients are unable to engage in full time employment. There is a need to educate the public regarding higher cost of care by traditional healers and other informal modes of treatment compared to Western medical care.

\section{References}

1. Knapp M, Mangalore R, Simon J. The global costs of schizophrenia. Schizophrenia Bulletin 2004; 30: 279-93.

2. Andrews G, Hall W, Goldstein G, et al. The economic costs of schizophrenia: implications for public policy. Archives of General Psychiatry 1985; 42: 537-43.

3. Russel S, Gilson L. Are health services protecting the livelihoods of the urban poor in Sri Lanka? Findings from two low-income areas of Colombo. Social Science and Medicine 2006; 63: 1732-44.

4. McIntyre D, Thiede M, Dahlgren G, Whitehead M. What are the economic consequences for households of illness and of paying for health care in low- and middle-income country contexts? Social Science and Medicine 2006; 62: 858-65.

5. Garg CC, Karan AK. Reducing out-of-pocket expenditures to reduce poverty: a disaggregated analysis at rural-urban and state level in India. Health Policy and Planning 2009; 24: 116-28.

6. Attanayake N, Fox-Rushby J, Mills A. Household costs of 'malaria' morbidity: a study in Matale district, Sri Lanka. Tropical Medicine and International Health 2000; 5: 595-606.

7. Lahariya C, Singhal S, Gupta S, Mishra A. Pathway of care among psychiatric patients attending a mental health institution in central India. Indian Journal of Psychiatry 2010; 52: 333-8.

8. Grover S, Avasthi A, Chakrabarti S, Bhansali A, Kulhara P. Cost of care of schizophrenia: a study of Indian outpatient attenders. Acta Psychiatrica Scandinavica 2005; 112: $54-63$.

9. Kawabata K, Xu K, Carrin G. Preventing impoverishment through protection against catastrophic health expenditure. Bulletin of the World Health Organization 2002; 80: 612.

10. Ranson. Reduction of catastrophic health care expenditures by a community-based health insurance scheme in Gujurat, India: current experiences and challenges. Bulletin of the World Health Organization 2002; 80: 613-21.

11. Russell S. Illuminating cases: understanding the economic burden of illness through case study household research. Health Policy and Planning 2005; 20: 277-89. 